\title{
Effects of renal sympathetic denervation on 24-hour blood pressure variability
}

\section{Christine S. Zuern ${ }^{1}$, Konstantinos D. Rizas ${ }^{1}$, Christian Eick ${ }^{1}$, Cosmina Stoleriu ${ }^{1}$, Lena Bunk ${ }^{1}$, Petra Barthel ${ }^{2}$, Bernd Balletshofer ${ }^{3}$, Meinrad Gawaz ${ }^{1}$ and Axel Bauer ${ }^{1 *}$}

Innere Medizin III (Kardiologie), Eberhard-Karls-Universität Tübingen, Tübingen, Germany

${ }^{2}$ Medizinische Klinik I, Technische Universität München, München, Germany

${ }^{3}$ Innere Medizin IV (Endokrinologie/Diabetes, Nephrologie und Angiologie), Eberhard-Karls-Universität Tübingen, Tübingen, Germany

\section{Edited by:}

Derek John Hausenloy, University

College London, UK

Reviewed by:

Celena Scheede-Bergdahl, McGill

University, Canada

Xuejun Wang, University of South

Dakota, USA

*Correspondence:

Axel Bauer, Innere Medizin III,

Kardiologie und

Kreislauferkrankungen,

Otfried-Müller-Str. 10, 72076

Tübingen, Germany.

e-mail:axel.bauer@med.

uni-tuebingen.de
Background: In patients with arterial hypertension, increased blood pressure (BP) variability contributes to end organ damage independently from mean levels of arterial BP. Increased BP variability has been linked to alterations in autonomic function including sympathetic overdrive. We hypothesized that catheter-based renal sympathetic denervation (RDN) confers beneficial effects on BP variability. Methods and Results: Eleven consecutive patients with therapy-refractory arterial hypertension (age 68.9 \pm 7.0 years; baseline systolic BP $189 \pm 23 \mathrm{mmHg}$ despite medication with $5.6 \pm 2.1$ antihypertensive drugs) underwent bilateral RDN. Twenty-four hour ambulatory BP monitoring (ABPM) was performed before RDN and 6 months thereafter. BP variability was primarily assessed by means of standard deviation of 24-h systolic arterial BP (SDsys). Secondary measures of $\mathrm{BP}$ variability were maximum systolic $\mathrm{BP}\left(\mathrm{MAX}_{\text {sys }}\right)$ and maximum difference between two consecutive readings of systolic BP ( $\Delta$ max $_{\text {sys }}$ ) over $24 \mathrm{~h}$. Six months after RDN, $\mathrm{SD}_{\text {sys, }}$ $\mathrm{MAX}_{\text {sys, }}$ and $\Delta$ max $_{\text {sys }}$ were significantly reduced from $16.9 \pm 4.6$ to $13.5 \pm 2.5 \mathrm{mmHg}$ $(p=0.003)$, from $190 \pm 22$ to $172 \pm 20 \mathrm{mmHg}(p<0.001)$, and from $40 \pm 15$ to $28 \pm 7 \mathrm{mmHg}$ $(p=0.006)$, respectively, without changes in concomitant antihypertensive therapy. Reductions of $\mathrm{SD}_{\text {sys }}, \mathrm{MAX}_{\text {sys }}$, and $\Delta$ max $_{\text {sys }}$ were observed in 10/11 (90.9\%), 11/11 (100\%), and $9 / 11(81.8 \%)$ patients, respectively. Although we noted a significant reduction of systolic office BP by $30.4 \pm 27.7 \mathrm{mmHg}(p=0.007)$, there was only a trend in reduction of average systolic BP assessed from ABPM (149 \pm 19 to $142 \pm 18 \mathrm{mmHg} ; p=0.086)$. Conclusion: In patients with therapy-refractory arterial hypertension, RDN leads to significant reductions of $\mathrm{BP}$ variability. Effects of RDN on BP variability over $24 \mathrm{~h}$ were more pronounced than on average levels of BP.

Keywords: arterial hypertension, renal sympathetic denervation, blood pressure variability

\section{INTRODUCTION}

Reductions of systolic and diastolic blood pressure (BP) are the primary goal in treatment of arterial hypertension (Mancia et al., 2007b). Several large-scale studies demonstrated a clear relationship between level of BP and cardiovascular risk. However, even under physiologic conditions BP is a highly variable parameter influenced by a variety of intrinsic and extrinsic factors. There is sound evidence that increased BP variability and instability contribute to end organ damage, independently from absolute BP levels (Parati et al., 1987; Frattola et al., 1993; Sander et al., 2000; Mancia et al., 2001; Pringle et al., 2003; Hansen et al., 2010; Rothwell et al., 2010b). Patients with treatment-resistant BP variability are known to have a poor prognosis even if their mean BP is under control (Rothwell, 2010; Rothwell et al., 2010b). Therefore, knowledge about the effect of an antihypertensive therapy on BP variability is of clinical importance.

Several factors have been associated with increased BP variability including advanced age, diabetes mellitus, and female gender (Mancia et al., 1983; Rothwell, 2010; Schillaci and Parati, 2010).
However, the exact pathophysiological mechanisms underlying abnormal BP variability and instability are still debated. Autonomic factors including sympathetic overactivity and blunted arterial baroreflex function are most likely involved (Mancia et al., 1983, 1997; Rothwell, 2010; Schillaci et al., 2011).

Catheter-based renal sympathetic denervation (RDN) is a novel treatment option for patients with uncontrolled essential arterial hypertension (Krum et al., 2009; Esler et al., 2010). Basic principle of RDN is bilateral radiofrequency ablation of afferent and efferent sympathetic nerves located in the adventitia of the renal artery. RDN has been shown to effectively reduce systolic and diastolic BP most probably due to a reduction in both renal and central sympathetic activity (Krum et al., 2009; Esler et al., 2010). RDN reduces whole body norepinephrine spillover by $42 \%$ and efferent muscle sympathetic nerve activity by $66 \%$ (Schlaich et al., 2009). However, effects of RDN on BP variability and instability are entirely unknown.

In the present study, we tested the hypothesis that RDN leads to a significant reduction of abnormal BP variability and instability 
in patients with therapy-refractory arterial hypertension in dependently from a reduction in mean BP levels.

\section{MATERIALS AND METHODS PATIENTS}

The present study included the first 11 patients who underwent $\mathrm{RDN}$ in our hospital. All patients suffered from therapy-refractory arterial hypertension. Enrollment criteria were identical to those used in previous studies (Krum et al., 2009; Esler et al., 2010). Patients were above 18 years of age, had an office systolic BP of $\geq 160 \mathrm{mmHg}(\geq 150 \mathrm{mmHg}$ for patients with type 2 diabetes mellitus) despite being treated with at least three antihypertensive drugs (including one diuretic), with no changes in medication for a minimum of 2 weeks before enrollment. Patients were included if they were not pregnant and had an estimated glomerular filtration rate $\geq 45 \mathrm{~mL} \mathrm{~min}^{-1} 1.73 \mathrm{~m}^{-2}$ (using the Modified Diet in Renal Disease formula). All patients underwent a complete history and physical examination, assessment of vital signs, review of medication, and blood chemistry at baseline and after 6 months. Physicians were instructed not to change antihypertensive medications except when medically required. Patients were instructed to remain adherent to their prescribed drugs and defined doses during follow-up. The study was approved by the ethic committee of the University of Tübingen. All patients gave written informed consent.

\section{RENAL DENERVATION PROCEDURE}

Patients underwent RDN between October 2010 and March 2011. Details of RDN have been described elsewhere (Krum et al., 2009; Esler et al., 2010). Renal angiograms were performed via femoral access to confirm anatomic eligibility. The treatment catheter (Flex by Ardian/Medtronic Inc., Mountain View, USA) was introduced into each renal artery using a guiding catheter. Up to six ablations at eight watts for 2 min each were performed in both renal arteries. Treatments were delivered from the first distal main renal artery bifurcation to the ostium proximally and were spaced longitudinally and rotationally under fluoroscopic guidance. Catheter tip impedance and temperature were constantly monitored, and radio frequency energy delivery was regulated according to a predetermined algorithm. Visceral pain at the time of energy delivery was managed with intravenous analgesics and sedatives. Heparin was given to achieve an activated clotting time during the procedure of more than $250 \mathrm{~s}$.

\section{ASSESSMENT OF BP, BP VARIABILITY, AND INSTABILITY}

Office BP readings were taken in a seated position after $5 \mathrm{~min}$ of rest according to the standard Joint National Committee VII guidelines before ablation and 6 months thereafter (Chobanian et al., 2003). Averages of triplicate consecutive measures were used. Patients with reductions of systolic office BP of more than $10 \mathrm{mmHg}$ were regarded as responders (Mahfoud et al., 2011).

In all patients, 24-h ambulatory BP monitoring (ABPM; oscillometric Spacelabs 90207-32 monitor, Spacelabs Healthcare, Issaquah, WA, USA) was performed before RDN and 6 months thereafter. Readings were taken every 20 min during daytime and every $60 \mathrm{~min}$ at night-time. Only ambulatory BP assessments that met European Society of Cardiology and European Society of
Hypertension guidelines (with more than $70 \%$ of daytime and night-time readings) were regarded as technically sufficient for inclusion in the analysis (Mancia et al., 2007b). Mean systolic and diastolic BP was calculated as overall 24-h averages for every patient. BP variability was assessed by the standard deviation of systolic and diastolic $\mathrm{BP}\left(\mathrm{SD}_{\text {sys }}\right.$ and $\mathrm{SD}_{\text {dia }}$; Mancia et al., 2007b), the maximum systolic and diastolic $\mathrm{BP}\left(\mathrm{MAX}_{\mathrm{sys}}\right.$ and $\left.\mathrm{MAX}_{\mathrm{dia}}\right)$, and the maximum difference of systolic and diastolic BP observed between two consecutive readings $\left(\Delta \max _{\text {sys }}\right.$ and $\Delta \max _{\text {dia }}$ ). Mean and standard deviations of systolic and diastolic $\mathrm{BP}$ were also calculated for day (10 AM-8 PM) and night-time (12 AM-6 AM). The coefficient of variation of systolic and diastolic $\mathrm{BP}$ was assessed by dividing $\mathrm{SD}$ by mean. We also assessed the morning surge, i.e., the maximum increase in systolic and diastolic BP between $4 \mathrm{AM}$ and $10 \mathrm{AM}$.

\section{STATISTICAL ANALYSIS}

Data are expressed as mean \pm standard deviation. Wilcoxon signed-rank test for two related samples was used to compare continuous variables assessed before and after RDN. All tests of significance were two-sided. Analyses of the effects of RDN on $\mathrm{SD}_{\text {sys }}$ were specified as primary analyses. Analyses of the effects of RDN on other measures of BP were only exploratory. Pearson's correlation was used to test the correlation between continuous variables. A two-tailed $p$-value $<0.05$ was considered statistically significant.

Taking into consideration the effects of calcium antagonists on our primary variable (Frattola et al., 2000) we hypothesized a minimum $\mathrm{RDN}$-induced reduction of $30 \%$ in $\mathrm{SD}_{\text {sys. }}$. To achieve a power of $90 \%$ with a standard deviation of $\mathrm{SD}_{\text {sys }}=3.8 \mathrm{mmHg}$ (Mancia et al., 2001) we calculated the minimum required sample size for a paired analysis to $n=8$ (R CRAN 2.13.1, package sample size).

SPSS software for Windows (version 13.0; SPSS, Chicago, IL, USA) was used for all other statistical analyses.

\section{RESULTS}

Tables 1 and 2 show the demographic indicators and clinical characteristics. Three patients were female. Mean age was 68.9 (7.0) years. On average, patients were taking 5.6 (2.1) antihypertensive drugs. All patients received an angiotensin-converting enzyme inhibitor, angiotensin II receptor blocker, or both; six patients $(54.5 \%)$ received a direct renin-inhibitor, eight patients $(72.7 \%)$ received $\beta$-blockers; nine $(81.8 \%)$ were taking calcium channel blockers; and eight (72.7\%) received centrally acting sympatholytic agents. Two patients were on vasodilators (18.2\%) and four on $\alpha$-blockers (36.4\%). All patients received diuretics, with 2 $(18.2 \%)$ taking aldosterone antagonists.

Renal sympathetic denervation was performed in all patients without periprocedural complications. Patients were instructed not to change their antihypertensive medications unless adverse effects occurred. At 6 months after ablation, there was a slight, not statistically significant reduction in the number of antihypertensive drugs from 5.6 (2.1) to 5.4 (2.0; Table 2). One patient stopped taking a direct renin-inhibitor, one patient stopped taking a calcium-channel blocker, one patient stopped taking a vasodilator, and one patient stopped taking an aldosterone antagonist. 
Table 1 | Baseline clinical characteristics and demographics.

\begin{tabular}{ll}
\hline Baseline office systolic BP $(\mathrm{mmHg})$ & $189(23)$ \\
Baseline office diastolic BP $(\mathrm{mmHg})$ & $92(15)$ \\
Age (years) & $68.9(7.0)$ \\
Sex (female) & $3(27.3)$ \\
Body-mass index $\left(\mathrm{kg} / \mathrm{m}^{2}\right)$ & $29.0(3.4)$ \\
Diabetes mellitus & $4(36.4)$ \\
Coronary artery disease & $4(36.4)$ \\
Left ventricular ejection fraction (\%) & $59.1(3.0)$ \\
Hypercholesterolaemia & $4(36.4)$ \\
eGFR (mL/min/1.73 $\left.\mathrm{m}^{2}\right)$ & $75.0(18.4)$ \\
Serum creatinine $(\mu \mathrm{mol} / \mathrm{L})$ & $1.0(0.2)$
\end{tabular}

Data are mean (SD) or number (\%). BP, blood pressure; eGFR, estimated glomerular filtration rate.

Table 2 | Antihypertensive medications before and $\mathbf{6}$ months after renal denervation.

\begin{tabular}{lll}
\hline & $\begin{array}{l}\text { Before renal } \\
\text { denervation }\end{array}$ & $\begin{array}{l}\mathbf{6} \text { months } \\
\text { follow-up }\end{array}$ \\
\hline $\begin{array}{l}\text { Number of antihypertensive drugs } \\
\text { Patients on five or more medications }\end{array}$ & $5.6(2.1)$ & $5.4(2.0)$ \\
PATIENTS RECEIVING (DRUG CLASS) & & $6(54.5)$ \\
ACE inhibitors/ARBs & $11(100)$ & $11(100)$ \\
Direct renin inhibitor & $6(54.5)$ & $5(45.5)$ \\
$\beta$-Blockers & $8(72.7)$ & $8(72.7)$ \\
Calcium-channel blockers & $9(81.8)$ & $8(72.7)$ \\
Diuretics & $11(100)$ & $11(100)$ \\
Aldosterone antagonist & $2(18.2)$ & $2(18.2)$ \\
Vasodilators & $2(18.2)$ & $1(9.1)$ \\
$\alpha$-Blockers & $4(36.4)$ & $3(27.3)$ \\
Centrally acting sympatholytics & $8(72.7)$ & $8(72.7)$ \\
\hline
\end{tabular}

Data are mean (SD) or number (\%). ACE, angiotensin-converting enzyme; $A R B$, angiotensin-receptor blocker.

At baseline, overall mean sitting office systolic BP was $189 \pm 23 \mathrm{mmHg}$, and mean sitting office diastolic BP was $92 \pm 15 \mathrm{~mm} \mathrm{Hg}$, with a heart rate of $67 \pm 11 \mathrm{bpm}$. Renal denervation significantly reduced systolic $(-30.4 \pm 27.7 \mathrm{~mm} \mathrm{Hg}$; $p=0.007)$ but not diastolic $(-2.9 \pm 16.1 \mathrm{~mm} \mathrm{Hg} ; P=0.648) \mathrm{BP}$ at 6 months after the procedure. Nine of the 11 patients $(81.8 \%)$ were responders to RDN as defined by a reduction in systolic office $\mathrm{BP}$ of $>10 \mathrm{mmHg}$.

Renal sympathetic denervation had significant effects on BP variability: It reduced $\mathrm{SD}_{\text {sys }}$ by $20.1 \%$ from $16.9 \pm 4.6$ to $13.5 \pm 2.5 \mathrm{mmHg}(p=0.003), \mathrm{MAX}_{\text {sys }}$ by $17.8 \mathrm{mmHg}$ from $190 \pm 22$ to $172 \pm 20 \mathrm{mmHg}(p<0.001)$, and $\Delta \max _{\mathrm{sys}}$ by $25 \%$ from $40 \pm 15$ to $28 \pm 7$ ( $p=0.006$; Table 3; Figures 1A,C,E). Reductions of $\mathrm{SD}_{\text {sys }}, \mathrm{MAX}_{\mathrm{sys}}$, and $\Delta \max _{\mathrm{sys}}$ were observed in 10/11 (90.9\%), 11/11 (100\%), and 9/11 (81.8\%), respectively. Changes were also significant when the coefficient of variation of systolic BP was considered $(p=0.024)$. Corresponding changes of BP variability in diastolic pressures were also significant $\left(p=0.007, p=0.043\right.$, and $p=0.011$ for $\mathrm{SD}_{\mathrm{dia}}, \mathrm{MAX}_{\mathrm{dia}}$, and $\Delta \max _{\text {dia }}$, respectively; Table 3; Figures 1B,D,F).

We also noted significant effects of RDN on 24-h $\mathrm{SD}_{\text {sys }}$ and $\mathrm{SD}_{\text {dia }}$ when assessed for daytime but not for night-time (Table 3 ). Renal denervation also reduced the morning surge assessed by maximum increase of systolic and diastolic BP between $4 \mathrm{AM}$ and $10 \mathrm{AM}$.

In contrast to effects of RDN on office systolic BP, RDN demonstrated a less pronounced reduction in mean systolic BP assessed by means of ABPM, which did not reach the level of statistical significance (Figure 2). Six months after RDN, mean systolic BP was reduced by $7 \mathrm{mmHg}$ from $149 \pm 19$ to $142 \pm 18 \mathrm{mmHg}$ $(p=0.086)$.

We did not find any statistically significant correlation between RDN-related changes of BP variability (i.e., BP variability before minus $\mathrm{BP}$ variability after $\mathrm{RDN}$ ) and $\mathrm{RDN}$-related changes of mean BP levels, neither for systolic nor for diastolic BP. In particular, the correlation between RDN-related change of $\mathrm{SD}_{\text {sys }}$ and RDN-related change of $\mathrm{Mean}_{\text {sys }}$ was found $-0.06(p=0.856)$. This remained true, when changes of $\mathrm{BP}$ variability were correlated with changes of office BP, when day- and night-time were separately analyzed or when analyses were restricted to RDN-responders.

\section{DISCUSSION}

The findings of our study indicate that RDN has significant effects on 24-h BP variability and instability in patients with therapyrefractory arterial hypertension. Reduction of 24-h BP variability by means of standard deviation of systolic BP was present in 10 out of 11 patients. RDN was also found to affect other estimates of BP variability and instability such as the maximum systolic $\mathrm{BP}$ or the maximum difference between consecutive BP readings. Importantly, changes in $\mathrm{BP}$ variability and instability before and after RDN were not correlated with changes in 24-h mean levels of $\mathrm{BP}$ which were less pronounced.

Catheter-based RDN is a novel treatment option for patients with treatment-resistant arterial hypertension. Its potential in reducing office $\mathrm{BP}$ has been demonstrated in one observational (Krum et al., 2009) and one randomized trial (Esler et al., 2010). In our study RDN reduced systolic office BP by $30 \pm 28 \mathrm{mmHg}$ which is practically identical to the results noted in previous studies (Krum et al., 2009; Esler et al., 2010). RDN's effect on reducing BP is most likely carried by a decline in renal and central sympathetic activity (Krum et al., 2009; Esler et al., 2010). Published studies investigating the effect of RDN on 24-h ABPM primarily focus on reporting mean $\mathrm{BP}$ values, which according to our results are less affected by RDN. In the Symplicity-II trial RDN reduced mean 24-h systolic BP by only $11 \pm 15 \mathrm{mmHg}$ (Esler et al., 2010).

However, the analysis of 24-h BP profiles provides important insights into (patho-) physiological regulations and prognostic information beyond assessment of mean BP. Over 20 years ago, Parati et al. (1987) demonstrated in 108 hypertensive patients that the standard deviation of systolic BP was associated with end organ damage independently from mean systolic BP. Several other studies confirmed the independent value of 24-h BP variability in predicting organ damage (Mancia et al., 2001). Increased BP variability also proved as a significant and independent predictor of clinical events, particularly of stroke, both in patients with 
Table 3 | BP variability, instability, and mean levels of BP at baseline and 6 months after ablation.

\begin{tabular}{|c|c|c|c|c|c|c|}
\hline & \multicolumn{3}{|c|}{ Systolic BP } & \multicolumn{3}{|c|}{ Diastolic BP } \\
\hline & $\begin{array}{l}\text { Before renal } \\
\text { denervation }\end{array}$ & $\begin{array}{l}6 \text { months } \\
\text { follow-up }\end{array}$ & $p$-Value & $\begin{array}{l}\text { Before renal } \\
\text { denervation }\end{array}$ & $\begin{array}{l}6 \text { months } \\
\text { follow-up }\end{array}$ & $p$-Value \\
\hline \multicolumn{7}{|l|}{ BP VARIABILITY AND INSTABILITY (ABPM) } \\
\hline \multicolumn{7}{|l|}{ Standard deviation, $\mathrm{mmHg}$} \\
\hline $24 \mathrm{~h}$ & $16.9 \pm 4.6$ & $13.5 \pm 2.5$ & 0.003 & $11.2 \pm 2.9$ & $8.6 \pm 1.9$ & 0.007 \\
\hline Daytime (10 AM-8 PM) & $15.1 \pm 4.1$ & $11.7 \pm 2.1$ & 0.005 & $10.7 \pm 3.5$ & $7.5 \pm 1.3$ & 0.010 \\
\hline Night-time (12 AM-6 AM) & $12.7 \pm 6.1$ & $10.0 \pm 4.4$ & 0.365 & $9.1 \pm 3.8$ & $7.5 \pm 3.1$ & 0.175 \\
\hline Coefficient of variation & $0.11 \pm 0.03$ & $0.09 \pm 0.02$ & 0.041 & $0.14 \pm 0.03$ & $0.11 \pm 0.02$ & 0.024 \\
\hline Maximum (24 h), mmHg & $190 \pm 22$ & $172 \pm 20$ & $<0.001$ & $112 \pm 25$ & $98 \pm 18$ & 0.043 \\
\hline$\Delta$ max of consecutive readings ( $24 \mathrm{~h}), \mathrm{mmHg}$ & $40 \pm 15$ & $28 \pm 7$ & 0.006 & $37 \pm 11$ & $20 \pm 5$ & 0.011 \\
\hline Maximum increase from $4 \mathrm{AM}$ to $10 \mathrm{AM}, \mathrm{mmHg}$ & $53 \pm 19$ & $40 \pm 17$ & 0.058 & $32 \pm 20$ & $25 \pm 11$ & 0.035 \\
\hline \multicolumn{7}{|l|}{ MEAN LEVELS (OFFICE AND ABPM) } \\
\hline Office $\mathrm{BP}, \mathrm{mmHg}$ & $189 \pm 23$ & $158 \pm 24$ & 0.007 & $92 \pm 15$ & $88 \pm 17$ & 0.648 \\
\hline \multicolumn{7}{|l|}{ Mean ABPM, mmHg } \\
\hline $24 \mathrm{~h}$ & $149 \pm 19$ & $142 \pm 18$ & 0.086 & $82 \pm 17$ & $79 \pm 15$ & 0.167 \\
\hline Daytime (10 AM-8 PM) & $155 \pm 22$ & $145 \pm 22$ & 0.083 & $85 \pm 17$ & $81 \pm 16$ & 0.206 \\
\hline Night-time (12 AM-6 AM) & $137 \pm 17$ & $136 \pm 16$ & 0.966 & $74 \pm 15$ & $74 \pm 14$ & 0.781 \\
\hline
\end{tabular}

ABPM, ambulatory blood pressure monitoring; BP, blood pressure.

pre-existent hypertension (Pringle et al., 2003) and in the general population (Mancia et al., 2007a). However, not all studies did find the predictive value of 24-h BP variability to be independent from mean BP (Hansen et al., 2010). Other investigations assessed $\mathrm{BP}$ variability over longer time scales by analyzing day-to-day or visit-to-visit $\mathrm{BP}$ variability, which might capture different facets of BP regulations. In most of these studies, day-to-day or visit-tovisit variability was a strong and independent predictor of stroke (Kikuya et al., 2000), cardiovascular mortality (Kikuya et al., 2000), or all cause mortality (Muntner et al., 2011; Hsieh et al., 2012). This was true for studies including the general population (Kikuya et al., 2000), patients with previous transitory ischemic attack (Rothwell et al., 2010b), patients with treated hypertension (Rothwell et al., 2010b), or type 2 diabetics (Hsieh et al., 2012). Additional markers of BP instability such as the maximum observed systolic BP were also predictive for clinical events (Rothwell et al., 2010b).

It might be suggested that drugs, which favorably affect mean $\mathrm{BP}$, also reduce $\mathrm{BP}$ variability. However, this might not be true as recent findings in different populations suggest (Frattola et al., 2000; Rothwell et al., 2010a; Webb et al., 2010; Webb and Rothwell, 2011; Zhang et al., 2011). Only calcium antagonists have been shown to reduce BP variability (visit-to-visit as well as 24-h), while $\beta$-blockers, angiotensin-converting enzyme inhibitors, and angiotensin II receptor antagonists seem to exhibit opposite effects (Frattola et al., 2000; Rothwell et al., 2010a; Webb et al., 2010; Webb and Rothwell, 2011; Zhang et al., 2011). These findings are alarming, as patients with residual BP variability on treatment have an adverse prognosis despite control of mean BP (Rothwell et al., 2010b).

Despite awareness of the prognostic role of $\mathrm{BP}$ variability in the development of target organ damage and outcome a thorough knowledge of its underlying mechanisms is currently limited.
It is very likely that alterations in autonomic function including increased sympathetic activity and depressed baroreflex sensitivity are involved in increased BP variability (Schillaci et al., 2011). As baroreflex function ensures homeostasis, blunted baroreflex function may result in exaggerated BP fluctuations in response to extrinsic or intrinsic stimuli (Mancia et al., 1997). Since RDN has been shown to reduce renal and total sympathetic activity (Schlaich et al., 2009) and thus might exhibit favorable effects on baroreflex function in patients with sympathetic overactivity, it is plausible to assume that RDN leads to beneficial effects on BP variability. Additionally, other vascular mechanisms of BP variability have been proposed including alterations of arterial distensibility (Dabire et al., 2002).

A correct quantification of BP variability is of crucial importance. In the present study we used the simplest and probably most established measure of 24-h BP variability which is the standard deviation of BP. However, we are also aware of the fact that this approach has some shortcomings, as it is influenced by physiological variations such as day-night BP changes. Different mathematical approaches have been proposed to overcome this limitation (Mena et al., 2005; Mancia et al., 2007a). Separate assessment of day and night periods might be the most effective one. We also noted highly significant effects of RDN on daytime but not on night-time variations. A possible explanation for this lack of significance might be the reduced frequency of BP readings during night. Another possible explanation, however, could be that dayand night-time variations are differently affected by RDN with sympathetic overactivity playing its predominant role in affecting BP variability mainly during daytime. As recently suggested (Stergiou and Parati, 2011), BP instability was assessed by the maximum systolic BP, which has been recently found to be a strong and independent predictor of stroke (Rothwell et al., 2010b). 

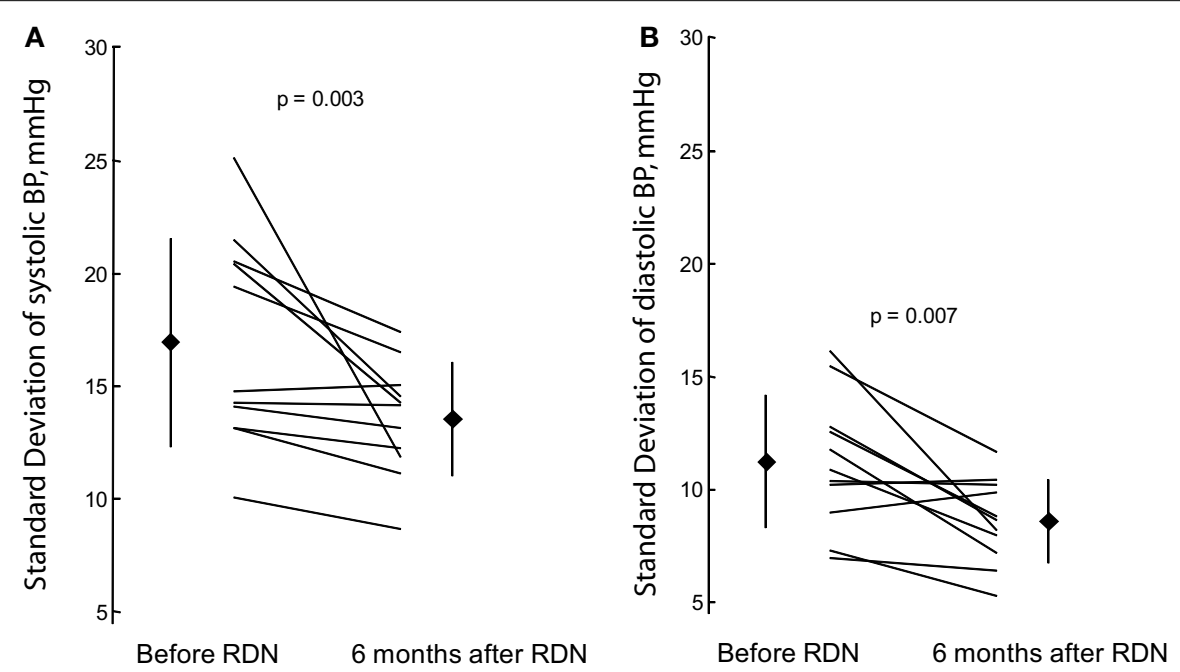

C

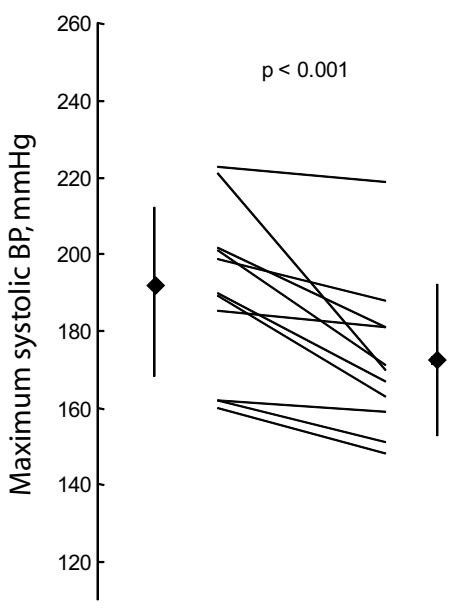

\section{D}
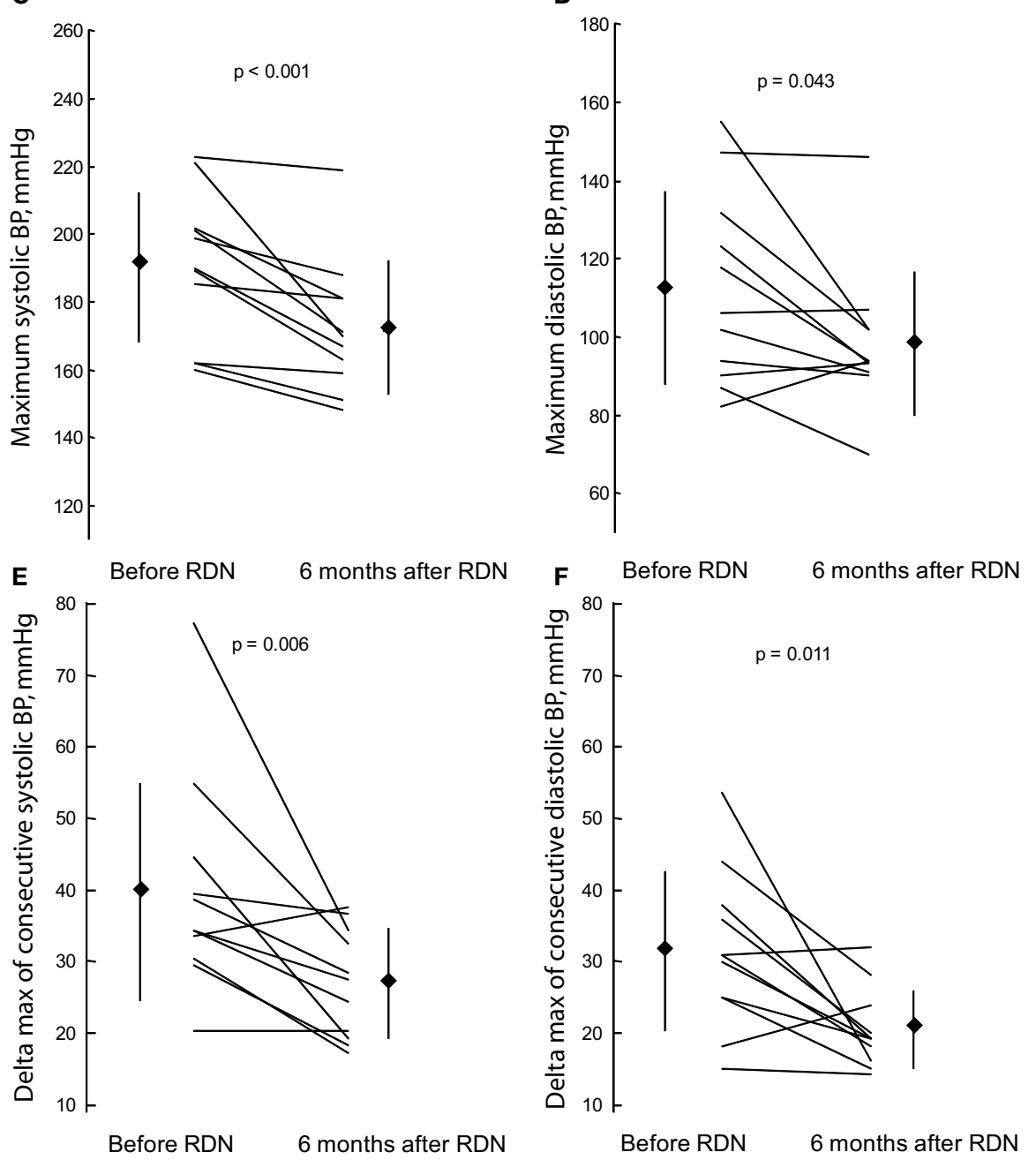

FIGURE 1 | Effect of renal sympathetic denervation (RDN) on blood pressure (BP) variability and instability: standard deviation of systolic (A) and diastolic (B) BP, maximum systolic (C) and diastolic (D) BP and

maximum difference of systolic $(E)$ and diastolic $(F)$ BP observed between two consecutive readings before renal sympathetic denervation and 6 months thereafter. 

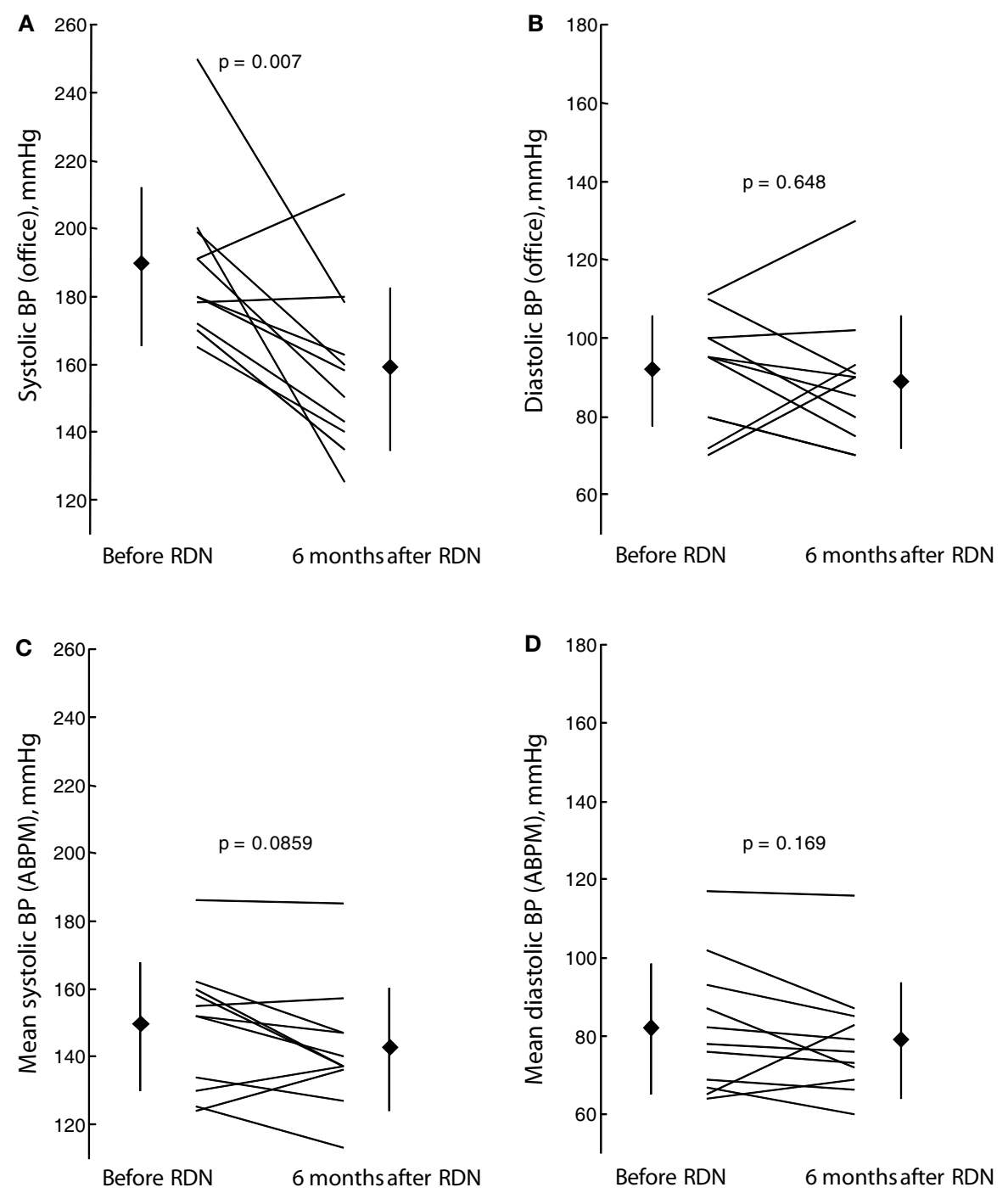

FIGURE 2 | Effect of renal sympathetic denervation (RDN) on mean levels of blood pressure (BP): office systolic (A) and diastolic (B) BP as well as mean levels of systolic (C) and

diastolic (D) blood BP on 24-h ambulatory BP monitoring (ABPM) before renal sympathetic denervation and 6 months thereafter.

Our study has important clinical implications. Increased BP variability and instability, which has been shown to predict adverse prognosis can be effectively treated by RDN. Previous studies have only identified calcium antagonists being able to reduce BP variability (Rothwell et al., 2010a; Webb et al., 2010; Webb and Rothwell, 2011; Zhang et al., 2011). Second, increased BP variability might help to identify responders to RDN. In the Symplicity-II study as much as $16 \%$ of the patients had RDNrelated decreases of systolic office BP of less than $10 \mathrm{mmHg}$. Third, previous studies identified increased BP variability as a strong predictor of stroke, particularly in patients with previous transitory ischemic attack (Rothwell et al., 2010b). Future studies should test whether this patient group might benefit from prophylactic RDN.

The limitations of our study need to be recognized. The study design was non-randomized and observational. However, our patients were well-controlled and antihypertensive treatment was

not intensified throughout the follow-up. Most of our patients were on calcium antagonists which might be a confounding factor. However, as therapy with calcium antagonists did not significantly change throughout the observational period, we do not believe that intake of calcium antagonists affects our results. The sample size of our study was small but sufficiently large to detect effects on the primary variable, i.e., standard deviation of $24-\mathrm{h}$ systolic BP. However, lack of significance in reduction of 24 -h mean BP $(p=0.083$ and $p=0.167$ for reductions of mean systolic and diastolic BP, respectively) might be due to a lack of statistical power. The small sample size also prevented us from analyzing effects of RDN on end organ damage. Furthermore, our study provides no mechanistic explanations of our findings as measures of sympathetic activity such as noradrenalin spillover or muscular sympathetic nerve activity have not been obtained.

In conclusion, RDN has significant beneficial effects on BP variability and instability in patients with therapy- 
refractory hypertension which are unrelated to and exceed effects on mean levels of BP. Potential beneficial effects of $\mathrm{RDN}$ on prognosis in hypertensive patients might be substantially mediated via a reduction of $\mathrm{BP}$ variability and instability.

\section{REFERENCES}

Chobanian, A. V., Bakris, G. L., Black, H. R., Cushman, W. C., Green, L. A., Izzo, J. L. Jr., Jones, D. W., Materson, B. J., Oparil, S., Wright, J. T. Jr., and Roccella, E. J. (2003). The seventh report of the Joint National Committee on Prevention, Detection, Evaluation, and Treatment of High Blood Pressure: the JNC 7 report. JAMA 289, 2560-2572.

Dabire, H., Lacolley, P., ChaoucheTeyara, K., Fournier, B., and Safar, M. E. (2002). Relationship between arterial distensibility and lowfrequency power spectrum of blood pressure in spontaneously hypertensive rats. J. Cardiovasc. Pharmacol. 39, 98-106.

Esler, M. D., Krum, H., Sobotka, P. A., Schlaich, M. P., Schmieder, R. E., and Bohm, M. (2010). Renal sympathetic denervation in patients with treatment-resistant hypertension (the symplicity HTN-2 trial): a randomised controlled trial. Lancet 376, 1903-1909.

Frattola, A., Parati, G., Castiglioni, P., Paleari, F., Ulian, L., Rovaris, G., Mauri, G., Di Rienzo, M., and Mancia, G. (2000). Lacidipine and blood pressure variability in diabetic hypertensive patients. Hypertension 36, 622-628.

Frattola, A., Parati, G., Cuspidi, C., Albini, F., and Mancia, G. (1993). Prognostic value of 24-hour blood pressure variability. J. Hypertens. 11, 1133-1137.

Hansen, T. W., Thijs, L., Li, Y., Boggia, J., Kikuya, M., Bjorklund-Bodegard, K., Richart, T., Ohkubo, T., Jeppesen, J., Torp-Pedersen, C., Dolan, E., Kuznetsova, T., Stolarz-Skrzypek, K., Tikhonoff, V., Malyutina, S., Casiglia, E., Nikitin, Y., Lind, L., Sandoya, E., Kawecka-Jaszcz, K., Imai, Y., Wang, J., Ibsen, H., O’Brien, E., and Staessen, J. A. (2010). Prognostic value of reading-toreading blood pressure variability over 24 hours in 8938 subjects from 11 populations. Hypertension 55, 1049-1057.

Hsieh, Y. T., Tu, S. T., Cho, T. J., Chang, S. J., Chen, J. F., and Hsieh, M. C. (2012). Visit-to-visit variability in blood pressure strongly predicts all-cause mortality in patients with type 2 diabetes: a 5.5-year prospective analysis. Eur. J. Clin. Invest. 42, 245-253.

Kikuya, M., Hozawa, A., Ohokubo, T., Tsuji, I., Michimata, M., Matsubara, M., Ota, M., Nagai, K., Araki, T., Satoh, H., Ito, S., Hisamichi, S., and Imai, Y. (2000). Prognostic significance of blood pressure and heart rate variabilities: the Ohasama study. Hypertension 36, 901-906.

Krum, H., Schlaich, M., Whitbourn, R., Sobotka, P. A., Sadowski, J., Bartus, K., Kapelak, B., Walton, A., Sievert, H., Thambar, S., Abraham, W. T., and Esler, M. (2009). Catheterbased renal sympathetic denervation for resistant hypertension: a multicentre safety and proof-ofprinciple cohort study. Lancet 373, 1275-1281.

Mahfoud, F., Schlaich, M., Kindermann, I., Ukena, C., Cremers, B., Brandt, M. C., Hoppe, U. C., Vonend, O., Rump, L. C., Sobotka, P. A., Krum, H., Esler, M., and Bohm, M. (2011). Effect of renal sympathetic denervation on glucose metabolism in patients with resistant hypertension: a pilot study. Circulation 123, 1940-1946.

Mancia, G., Bombelli, M., Facchetti, R., Madotto, F., Corrao, G., Trevano, F. Q., Grassi, G., and Sega, R. (2007a). Long-term prognostic value of blood pressure variability in the general population: results of the Pressioni Arteriose Monitorate e LoroAssociazioni Study. Hypertension 49, 1265-1270.

Mancia, G., De Backer, G., Dominiczak, A., Cifkova, R., Fagard, R., Germano, G., Grassi, G., Heagerty, A. M., Kjeldsen, S. E., Laurent, S., Narkiewicz, K., Ruilope, L., Rynkiewicz, A., Schmieder, R. E., Struijker-Boudier, H. A., Zanchetti, A., Vahanian, A., Camm, J., De Caterina, R., Dean, V., Dickstein, K., Filippatos, G., FunckBrentano, C., Hellemans, I., Kristensen, S. D., Mcgregor, K., Sechtem, U., Silber, S., Tendera, M., Widimsky, P., Zamorano, J. L., Erdine, S., Kiowski, W., Agabiti-Rosei, E., Ambrosioni, E., Lindholm, L. H., Manolis, A., Nilsson, P. M., Redon, J., Struijker-Boudier, H. A., Viigimaa, M., Adamopoulos, S., Bertomeu, V., Clement, D., Farsang, C., Gaita, D., Lip, G., Mallion, J. M., Manolis, A. J., O’Brien, E., Ponikowski, P.,

\section{ACKNOWLEDGMENTS}

Funding: The study was supported in part by grants from the program "Angewandte klinische Forschung" (AKF) of the University of Tübingen 252-1-0 to Axel Bauer. No additional external funding received for the study.

Ruschitzka, F., Tamargo, J., Van Zwieten, P., Waeber, B., Williams, B., The Task Force for the Management of Arterial Hypertension of the European Society of Hypertension, and The Task Force for the Management of Arterial Hypertension of the European Society of Cardiology. (2007b). 2007 Guidelines for the management of arterial hypertension: the Task Force for the Management of Arterial Hypertension of the European Society of Hypertension (ESH) and of the European Society of Cardiology (ESC). Eur. Heart J. 28, 1462-1536.

Mancia, G., Di Rienzo, M., Parati, G. and Grassi, G. (1997). Sympathetic activity, blood pressure variability and end organ damage in hypertension. J. Hum. Hypertens. 11(Suppl. 1), S3-S8.

Mancia, G., Ferrari, A., Gregorini, L., Parati, G., Pomidossi, G., Bertinieri, G., Grassi, G., Di Rienzo, M., Pedotti, A., and Zanchetti, A. (1983). Blood pressure and heart rate variabilities in normotensive and hypertensive human beings. Circ. Res. 53, 96-104.

Mancia, G., Parati, G., Hennig, M. Flatau, B., Omboni, S., Glavina, F., Costa, B., Scherz, R., Bond, G., and Zanchetti, A. (2001). Relation between blood pressure variability and carotid artery damage in hypertension: baseline data from the European Lacidipine Study on Atherosclerosis (ELSA). J. Hypertens. 19 1981-1989.

Mena, L., Pintos, S., Queipo, N. V., Aizpurua, J. A., Maestre, G., and Sulbaran, T. (2005). A reliable index for the prognostic significance of blood pressure variability. J. Hypertens. 23 , 505-511.

Muntner, P., Shimbo, D., Tonelli, M. Reynolds, K., Arnett, D. K., and Oparil, S. (2011). The relationship between visit-to-visit variability in systolic blood pressure and all-cause mortality in the general population: findings from NHANES III, 1988 to 1994. Hypertension 57, 160-166.

Parati, G., Pomidossi, G., Albini, F. Malaspina, D., and Mancia, G. (1987). Relationship of 24-hour blood pressure mean and variability to severity of target-organ damage in hypertension. J. Hypertens. 5, 93-98.
Pringle, E., Phillips, C., Thijs, L., Davidson, C., Staessen, J. A., De Leeuw, P. W., Jaaskivi, M., Nachev, C., Parati, G., O'Brien, E. T., Tuomilehto, J., Webster, J., Bulpitt, C. J., and Fagard, R. H. (2003). Systolic blood pressure variability as a risk factor for stroke and cardiovascular mortality in the elderly hypertensive population. J. Hypertens. 21, 2251-2257.

Rothwell, P. M. (2010). Limitations of the usual blood-pressure hypothesis and importance of variability, instability, and episodic hypertension. Lancet 375, 938-948.

Rothwell, P. M., Howard, S. C., Dolan, E., O’Brien, E., Dobson, J. E., Dahlof, B., Poulter, N. R., and Sever, P. S. (2010a). Effects of beta blockers and calcium-channel blockers on within-individual variability in blood pressure and risk of stroke. Lancet Neurol. 9, 469-480.

Rothwell, P. M., Howard, S. C., Dolan, E., O’Brien, E., Dobson, J. E., Dahlof, B., Sever, P. S., and Poulter, N. R. (2010b). Prognostic significance of visit-to-visit variability, maximum systolic blood pressure, and episodic hypertension. Lancet 375, 895-905.

Sander, D., Kukla, C., Klingelhofer, J., Winbeck, K., and Conrad, B. (2000). Relationship between circadian blood pressure patterns and progression of early carotid atherosclerosis: a 3-year follow-up study. Circulation 102, 1536-1541.

Schillaci, G., and Parati, G. (2010). Determinants of blood pressure variability in youth: at the roots of hypertension. J. Hypertens. 28, 660-664.

Schillaci, G., Pucci, G., and Parati, G. (2011). Blood pressure variability: an additional target for antihypertensive treatment? Hypertension 58, 133-135.

Schlaich, M. P., Sobotka, P. A., Krum, H., Lambert, E., and Esler, M. D. (2009). Renal sympathetic-nerve ablation for uncontrolled hypertension. $N$. Engl. J. Med. 361, 932-934.

Stergiou, G. S., and Parati, G. (2011). How to best assess blood pressure? The ongoing debate on the clinical value of blood pressure average and variability. Hypertension 57, 1041-1042.

Webb, A. J., Fischer, U., Mehta, Z., and Rothwell, P. M. (2010). Effects of 
antihypertensive-drug class on inter individual variation in blood pressure and risk of stroke: a systematic review and meta-analysis. Lancet 375, 906-915.

Webb, A. J., and Rothwell, P. M. (2011). Effect of dose and combination of antihypertensives on interindividual blood pressure variability: a systematic review. Stroke 42, 2860-2865.

Zhang, Y., Agnoletti, D., Safar, M. E., and Blacher, J. (2011). Effect of antihypertensive agents on blood pressure variability: the Natrilix SR versus candesartan and amlodipine in the reduction of systolic blood pressure in hypertensive patients (XCELLENT) study. Hypertension 58, 155-160.

Conflict of Interest Statement: The authors declare that the research was conducted in the absence of any commercial or financial relationships that could be construed as a potential conflict of interest.

Received: 15 February 2012; accepted: 21 April 2012; published online: 10 May 2012.

Citation: Zuern CS, Rizas KD, Eick C, Stoleriu C, Bunk L, Barthel P, Balletshofer B, Gawaz $M$ and Bauer A (2012) Effects of renal sympathetic denervation on 24-hour blood pressure variability. Front. Physio. 3:134. doi: 10.3389/fphys.2012.00134
This article was submitted to Frontiers in Clinical and Translational Physiology, a specialty of Frontiers in Physiology.

Copyright $\odot 2012$ Zuern, Rizas, Eick, Stoleriu, Bunk, Barthel, Balletshofer, Gawaz and Bauer. This is an openaccess article distributed under the terms of the Creative Commons Attribution Non Commercial License, which permits non-commercial use, distribution, and reproduction in other forums, provided the original authors and source are credited. 